\title{
Análise teórica e empírica dos determinantes dos fluxos de capitais financeiros para os países em desenvolvimento no contexto da globalização financeira
}

Theoretical and empirical analysis of the determinants of financial capital flows to developing countries in the context of financial globalization

Mauricio Andrade Weiss

Universidade Federal do Rio Grande do Sul

Daniela Magalhães Prates

Universidade Estadual de Campinas

\section{Abstract}

This article aims to contribute to the empirical literature on the determinants of financial capital flows to developing countries using an econometric panel data model with Generalized Method of Moments-System (GMM-S). As in former studies, the results showed the predominance of external factors over internal ones in determining capital flows. It is noteworthy the CBOE VIX volatility indicator, which showed significant and with the expected sign on the eleven tested equations. According to the postKeynesian perspective adopted in this paper, this indicator could be interpreted as an indicator of the liquidity preference of private agents. In tests relating to dummy for the years of crisis with the internal variables, the variables reservations about the external debt and current account deficit over GDP were statistically significant, with the first attenuated, while the second emphasized the impact of crisis.

\section{Keywords}

international monetary and financial system; capital flows; developing countries; panel data model; GMM-S.

JEL Codes C33; F32.

\section{Resumo}

Este artigo pretende dar uma contribuição à literatura empírica sobre os determinantes dos fluxos de capitais de natureza financeira direcionados aos paises em desenvolvimento por meio de um modelo econométrico de dados em painel com a utilização do Método dos Momentos Generalizados-Sistema (MMG-S). Os resultados obtidos corroboram os estudos anteriores que apontam para um predominio dos fatores externos sobre os internos na determinação desses fluxos. Merece destaque o indicador de volatilidade VIX $C B O E$, o qual pode ser interpretado, a partir de uma perspectiva pós-keynesiana, como um indicador de preferência por liquidez. Nos testes que relacionaram a dummy para os anos de crise com as variáveis internas, as variáveis reservas sobre o endividamento externo e sobre o déficit em transações correntes sobre o PIB se mostraram estatisticamente significativas, sendo que a primeira atenuou, enquanto a segunda acentuou o impacto das crises.

\section{Palavras-chave}

sistema monetário e financeiro internacional; fluxos de capitais; paises em desenvolvimento; dados em painel; $M M G-S$.

Códigos JEL C33; F32. 


\section{Introdução}

presente trabalho tem como principal objetivo dar uma contribuição à literatura empírica sobre os determinantes dos fluxos de capitais de natureza financeira (investimentos de portfólio e empréstimos bancários) por meio de testes com base no Método dos Momentos Generalizados (MMG). Adicionalmente, têm-se os seguintes objetivos específicos: i) realizar uma síntese da abordagem pós-keynesiana sobre a dinâmica dos fluxos de capitais após o colapso do regime de Bretton Woods, destacando a relação entre essa dinâmica e as características do Sistema Monetário e Financeiro Internacional (SMFI) contemporâneo; ii) revisar, de forma não extensiva, a literatura empírica sobre os determinantes dos fluxos financeiros para os países em desenvolvimento ${ }^{1}$ após sua inserção no processo de globalização financeira ${ }^{2}$; e iii) averiguar quais variáveis classificadas como pull-factors (fatores internos) seriam significativas na explicação da dinâmica desses fluxos nos momentos de crise, em especial, apurar se as reservas servem de atenuante nesses momentos.

Esse estudo empírico tem como embasamento teórico a abordagem pós-keynesiana, que destaca conceitos centrais para a análise da dinâmica dos fluxos de capitais no contexto da globalização financeira, tais como a incerteza, a preferência pela liquidez e as assimetrias do sistema monetário e financeiro internacional (SMFI) contemporâneo, que é um arranjo hierarquizado em torno de uma divisa-chave (o dólar fiduciário).

Ainda há muitas divergências na literatura sobre quais seriam os prin-

1 Neste artigo, o termo "países em desenvolvimento" engloba todos os países que ainda não atingiram o estágio de desenvolvimento. Neste sentido, incluem-se os países emergentes, os quais seriam os países em desenvolvimento que se inseriram na globalização financeira, tal como empregado por Prates (2002). Destarte, os países emergentes formam um subgrupo do grupo países em desenvolvimento. O Fundo Monetário Internacional (FMI) considera os países emergentes e os países em desenvolvimento como dois grupos distintos. O primeiro grupo refere-se aos países que atingiram um nível de desenvolvimento intermediário e que estão em vias de se tornarem países desenvolvidos. Já no segundo grupo estão os países ainda nos estágios iniciais de desenvolvimento. Esta classificação do FMI é especialmente importante porque são utilizadas diversas estatísticas fornecidas por essa instituição. Todavia, é importante estar claro que nessas estatísticas os dados referem-se à soma dos dois grupos (países emergentes e em desenvolvimento), que coincide com o conceito de países em desenvolvimento empregado neste artigo.

2 O conceito de globalização financeira adotado neste trabalho é o mesmo empregado por Prates (2002, p. 69), que se baseia em Chesnais (1994), qual seja: "A globalização financeira refere-se à eliminação das barreiras internas entre os diferentes segmentos dos mercados financeiros, somada à interpenetração dos mercados monetários e financeiros nacionais e sua integração aos mercados globalizados". 
cipais determinantes dos fluxos de capitais para os países em desenvolvimento. Essa controvérsia remonta ao início dos anos 1990, quando vários estudos procuraram identificar os determinantes da retomada desses fluxos de capitais no início dos anos 1999. De acordo com Isard (2005), o principal motivo para tal retomada teria sido a abertura financeira desses países a partir do final dos anos 1980 que, aliada à adoção do Plano Brady, teria impulsionado a reinserção desses países no mercado financeiro internacional. Já Prates (1999) aponta como principais determinantes do retorno dos fluxos de capitais privados naquele momento o contexto de redução da taxa de juros pelo Federal Reserve (Fed) e o movimento de diversificação de portfólio pelos agentes privados globais. Nesse sentido, a autora considera que a dinâmica desses fluxos é subordinada preponderantemente a condicionantes exógenos e que fatores internos aos países (os chamados fundamentos macroeconômicos) teriam apenas um papel secundário. $\mathrm{Na}$ mesma linha de argumentação, Biancareli (2006) sustenta que, apesar de fatores internos também influenciarem os fluxos de capitais, são os fatores exógenos à economia doméstica que determinam seu direcionamento.

O debate sobre a preponderância dos determinantes internos (pull factors) ou externos (push factors) na dinâmica dos fluxos de capitais aos países em desenvolvimento não se restringiu ao ciclo dos anos 1990. Também proliferaram estudos sobre os determinantes dos ciclos de fluxos de capitais no novo milênio. A maioria dos trabalhos empíricos refere-se aos fatores exógenos como sendo: rendimento em renda fixa e eventualmente renda variável de aplicações financeiras nos Estados Unidos, crescimento econômico dos países desenvolvidos e aversão ao risco dos agentes que atuam no mercado financeiro. Já os fatores internos incluem, principalmente, os indicadores de estabilidade macroeconômica e melhora da rentabilidade dos ativos domésticos (seja pela combinação de juros elevados com valorização cambial, seja pela expectativa de valorização da riqueza financeira até então depreciada).

Este artigo está divido em quatro seções, além desta introdução e da conclusão. A primeira seção faz uma síntese da abordagem pós-keynesiana para a dinâmica dos fluxos de capitais, destacando a relação entre essa dinâmica e as características do SMFI contemporâneo. A seção seguinte traz uma revisão, de forma não extensiva, dos trabalhos empíricos sobre os determinantes dos fluxos financeiros para os países em desenvolvimento após sua inserção no processo de globalização financeira. A terceira seção 
apresenta o método de análise e o modelo utilizado. A quarta e principal seção do trabalho apresenta os resultados do estudo empírico realizado sobre os determinantes dos fluxos financeiros para os países em desenvolvimento, o qual se diferencia dos demais estudos sobre o tema em função, sobretudo, de duas características: em primeiro lugar, pela abrangência do painel adotado, que incorporou 42 países em desenvolvimento de 4 diferentes continentes num período de 19 anos (de1990, quando esses países iniciaram sua inserção na globalização financeira, a 2008, ano da crise financeira global); em segundo lugar, estimou-se um modelo com 9 variáveis, constituindo 4 caracterizadas como push factors e 5 variáveis caracterizadas como pull factors, sendo que não se encontrou na revisão da literatura empírica tal combinação de variáveis. Inova-se também com a adoção da variável VIX CBOE, como representação da preferência por liquidez dos agentes privados globais. Ademais, a análise econométrica realizada, além de robusta e consistente, devido à utilização do Método dos Momentos Generalizados-Sistema (MMG-S) pela metodologia proposta por Windmeijer (2005), realizou testes adicionais para averiguar quais variáveis classificadas como pull-factors seriam significativas para determinar os fluxos de financeiros nos momentos de crise. Em especial, buscou-se averiguar se estratégias defensivas de aumento de reservas internacionais seria eficaz para atenuar os impactos das crises nos fluxos financeiros líquidos.

Os resultados do estudo empírico realizado sancionam a hipótese sustentada pela abordagem pós-keynesiana adotada como referencial teórico neste artigo, qual seja: de que os determinantes externos dos fluxos financeiros para os países em desenvolvimento são mais relevantes do que os determinantes internos.

\section{Revisão teórica}

A dinâmica dos fluxos de capitais de natureza financeira (investimentos de portfólio e empréstimos bancários) revelou-se altamente volátil após o colapso do sistema de Bretton Woods, em 1973 (Andrade; Prates, 2012). Essa volatilidade tem uma relação direta com as alterações nas preferências por liquidez dos agentes privados globais, a qual, por sua vez, está ligada intimamente à incerteza, entendida no sentido empregado por Keynes (1937): 
incerteza absoluta, que não pode ser confundida com risco probabilístico. ${ }^{3}$ Probabilidades são calculadas a partir de repetidas experiências em que são mantidas as mesmas condições. Para eventos macroeconômicos, as condições para se formar as probabilidades não seriam válidas. Isso porque, mesmo que se tenham informações sobre o passado e o presente, não há qualquer garantia de que as condições seriam mantidas no futuro (Davidson, 1983). ${ }^{4}$

A preferência por liquidez reflete o desejo de um agente de manter uma parcela ou totalidade da sua riqueza financeira em moeda ou ativos líquidos. $O$ grau de preferência por liquidez está diretamente associado à incerteza, que afeta as decisões dos agentes nas esferas industrial e financeira. Na esfera industrial, as pessoas necessitam de liquidez para honrar seus compromissos correntes (motivo-renda e finance) e futuros (motivo-precaução), os quais podem ser despesas ou oportunidades inesperadas. Este último motivo, que está relacionado com a preferência por liquidez, é o mais sensível às variações no grau de confiança dos agentes em suas previsões. Já na esfera financeira, o motivo especulação está relacionado com a tentativa de melhor interpretação do que ocorrerá no futuro. A incerteza quanto à taxa de juros futura afeta a preferência por liquidez no presente. Isso porque se uma redução na taxa de juros vigente resultar numa aposta de elevação dessa taxa no futuro (ou seja, queda do preço dos títulos), as pessoas preferirão manter sua riqueza na forma monetária (Keynes, 1983).

Para uma melhor compreensão do comportamento dos agentes privados relacionado ao motivo especulação, cabe uma explicação de como eles reagem diante da impossibilidade de realizar previsões confiáveis a respeito do futuro. De acordo com Keynes (1937, p. 114), o agente econômico utilizaria, principalmente, os seguintes mecanismos na tomada de decisão sob condições de incerteza: i) o presente é um melhor guia para o futuro do que as experiências passadas; ii) o estado existente da opinião expresso nos preços é baseado num resumo correto das perspectivas futuras, ao

3 No mainstream da economia, incerteza é sinônimo de risco probabilístico. Para mais detalhes entre distinções de risco probabilístico e incerteza ver Dequech (2000).

4 Keynes (1937, p. 113-114) define precisamente o que entende como incerteza: "By 'uncertain' knowledge, let me explain, I do not mean merely to distinguish what is known for certain from what is only probable. (...) The sense in which I am using the term is that in which the prospect of an European war is uncertain, or the price of copper and the rate of interest twenty years hence, or the obsolescence of a new invention, or the position of private wealth-owners in the social system in 1970. About these matters there is no scientific basis on which to form any calculable probability whatever. We simply do not know.". 
menos até que algo novo e relevante entre em cena; e iii) o julgamento com base nas convenções, isto é, a compreensão de que os demais agentes têm maior conhecimento que o indivíduo, o que implica uma tendência de mimetismo.

Como bem interpretado por Amado (2003, p. 6), embora esse comportamento baseado em convenções possa reduzir a percepção de incerteza para o indivíduo e, em certo aspecto, também para o coletivo, mudanças nas condições que sustentavam as percepções anteriores impactam as expectativas dos agentes, podendo provocar movimentos bruscos em direção à liquidez. Essa volatilidade pode ocorrer porque "o movimento das expectativas individuais ocorre no mesmo sentido, dado que a base convencional para a formação de expectativas é mantida". Ou seja, a tendência de mimetismo se mantém independentemente do grau de preferência por liquidez. Destarte, fuga para liquidez ou maior alocação em ativos de maior retorno, mas menos líquidos, são sempre acompanhados de movimentos bruscos devido ao comportamento baseado nas convenções, o que também pode ser entendido como efeito-manada.

A abordagem de Keynes sobre o comportamento convencional dos agentes privados num contexto de incerteza, sintetizada acima, circunscreveu-se a uma economia fechada. Quando se considera uma economia aberta, o perfil do sistema monetário internacional (SMI) deve ser introduzido na análise. As características do SMI contemporâneo, que emergiu após o colapso do sistema de Bretton Woods- dólar fiduciário como divisa-chave no topo da hierarquia de moedas, regime de câmbio flutuante e livre mobilidade de capitais (Prates, 2005) -imprimiram uma alta volatilidade dos fluxos de capitais, tornando ainda mais frágil o estado de convenções subjacente à tomada de decisão dos agentes privados globais.

A mudança da natureza da divisa-chave, que deixou de ser vinculada ao ouro e passou a ser exclusivamente fiduciária, concedeu um grau de autonomia de política econômica ainda maior ao país emissor, os Estados Unidos, já que seu passivo externo não é mais conversível na relíquia bárbara (Serrano, 2002). No entanto, como alerta Belluzzo (1997), a política monetária dos Estados Unidos não é completamente independente das decisões de alocação de portfólio dos agentes privados globais, uma vez que estando na situação de devedor líquido e deficitário na conta corrente do balanço de pagamentos, o país emissor da divisa-chave pode, eventualmente, exigir elevações da sua taxa de juros básica para atração do capital 
externo necessário. Mesmo que essa situação limite não se verifique, mudanças na taxa de juros da divisa-chave, associadas a objetivos internos (controle da inflação ou crescimento), afetam decisivamente a direção dos fluxos de capitais internacionais. Desse modo, a natureza fiduciária do dólar tornou a dinâmica desses fluxos e a política monetária do país emissor da divisa-chave ainda mais interligadas (Prates, 2005).

As duas demais características do SMI contemporâneo - livre mobilidade de capitais e regime de câmbio flutuante - também contribuíram para acentuar a volatilidade dos fluxos de capitais. $O$ fim dos controles sobre esses fluxos permitiu sua ampla mobilidade, acirrando a concorrência para atração dos capitais internacionais, que passaram a arbitrar em diferentes mercados em busca de maiores retornos. Enquanto, em momentos de otimismo, os investidores buscam a valorização do seu capital, em momentos de pessimismo e maior preferência pela liquidez em âmbito internacional, eles demandam o ativo mais líquido, qual seja, os títulos públicos dos Estados Unidos. Como o regime cambial é flutuante, as taxas de câmbio passam a ter movimentos bruscos, o que também abre oportunidades de ganhos especulativos nos mercados de câmbio, que reforçam ainda mais sua volatilidade (idem).

Também é importante ressaltar que não há uma relação simétrica entre a elevação e a redução na taxa de juros do país emissor da divisa-chave do SMI e a direção dos fluxos de capitais. Um aumento significativo nessa taxa de juros, supondo constantes as taxas de juros nos demais países, atrairá capitais para tal nação. Porém, uma redução não significará, necessariamente, saída de capitais, uma vez que os títulos de dívida pública desse país são o receptáculo da incerteza em âmbito internacional (Prates, 2005). Nesse caso, a direção dos fluxos de capitais dependerá do grau de aversão ao risco e de preferência de liquidez dos agentes privados globais.

Se, por um lado, o país emissor da divisa-chave é o maior receptor dos capitais nos momentos de incerteza, de outro lado, os países em desenvolvimento, emissores de moedas periféricas - que não desempenham nenhuma função da moeda em âmbito internacional e, assim, se situam no piso da hierarquia de moedas -são os mais sensíveis às mudanças nas expectativas dos agentes privadosglobais. Conforme argumenta Dow (1993), elevações na preferência por liquidez desses agentes provocarão uma fuga de capitais dos países em desenvolvimento em direção à divisa-chave ou ativos nela denominados. Como as mudanças de expectativas dos agentes tendem a 
ocorrer de forma mimética, os países emissores de moedas periféricas são os mais suscetíveis aos efeitos adversos dos movimentos de manada.

Assim, a dinâmica dos fluxos de capitais direcionados aos países emissores de moedas periféricas reflete uma das assimetrias do sistema financeiro internacional contemporâneo, que refere ao caráter exógeno dos fluxos de capitais aos países em desenvolvimento. Em outros termos, isso significa que há predominância dos push-factors sobre os pull-factors.

Países em desenvolvimento com mercados financeiramente abertos se tornam muito suscetíveis às mudanças de humor dos agentes privados globais. Sendo assim, as entradas de capitais nesses países podem cessar mesmo que não haja uma piora nas condições internas, sendo suficiente, como comentado acima, a alteração nas expectativas dos agentes privados globais. Contudo, indicadores macroeconômicos negativos poderiam elevar ainda mais a suscetibilidade dos países em desenvolvimento frente às alterações nos estados de confiança desses agentes. Sendo assim, entende-se que os países em desenvolvimento necessitam apresentar bons "fundamentos macroeconômicos", porém, eles não são suficientes para evitar saídas repentinas dos fluxos de capitais nos momentos de reversão das expectativas. Em contrapartida, em momentos de menor preferência pela liquidez dos agentes privados globais, há uma elevação na parcela de ativos de menor qualidade e maiores rendimentos em suas carteiras, entre os quais os títulos de renda fixa e ações dos países em desenvolvimento se enquadram (Prates, 2002; Cintra; Prates, 2006).

A segunda assimetria do sistema financeiro internacional diz respeito às diferenças de profundidade e liquidez dos mercados. De um lado, o volume dos fluxos de capitais destinados aos países em desenvolvimento é significativo frente à dimensão dos respectivos mercados financeiro e cambial. Desse modo, os recursos externos que ingressam nesses países em fases de grande otimismo podem alterar bruscamente as condições então vigentes. De outro lado, esse volume equivale a uma pequena parcela do portfólio dos grandes players internacionais; caso eles decidam alterar suas posições, seja por uma simples mudança de estratégia, seja pela reversão do ciclo de liquidez internacional, ocasionarão impactos severos nos fluxos de capitais para essas economias (Prates, 2002). Devido a essas possíveis saídas abruptas, os países em desenvolvimento se veem obrigados a manter elevadas reservas internacionais, as quais muitas vezes, decorrente do diferencial de juros, acarretam custos fiscais significativos. 


\section{Revisão empírica}

Um dos trabalhos empíricos pioneiros que buscou estimar a preponderância dos push e pull factors foi o de Calvo, Leiderman e Reinhart (1993). Os autores realizaram estimativas com base na técnica VAR para dez países latinos americanos durante o período que engloba janeiro de 1988 a dezembro de $1991 .{ }^{5}$ Os resultados obtidos apontam para a maior relevância dos fatores exógenos, em especial a taxa de juros dos Estados Unidos que havia se reduzido no período em questão.

Fernandez-Arias (1996)obteve resultados semelhantes ao estudo anterior, encontrando estimativas significativas entre a taxa de juros dos Estados Unidos e a entrada líquida dos fluxos financeiros. Além da importância direta dessa variável, ela mostrou-se determinante no comportamento do risco de crédito dos países em desenvolvimento. Ao mesmo tempo, variáveis internas, como o estoque de capital externo e o total das reservas internacionais não apresentaram resultados significativos.

Chuhan, Claessens e Mamingi (1993) e Taylor e Sarno (1997) realizaram estimações para investigar os determinantes dos investimentos de portfólio dos Estados Unidos em nove países latino-americanos e em nove países asiáticos entre janeiro de 1988 e setembro de 1992. Os resultados obtidos pelo primeiro trabalho indicam que os fluxos de capitais para os países latino-americanos são determinados de forma equivalente pelos fatores internos e externos, enquanto nos países asiáticos os fatores internos mostraram-se mais relevantes. O segundo trabalho concluiu que tanto os push factors como os pull fators são importantes determinantes de longo prazo dos investimentos em ações e títulos de renda fixa; em contrapartida, os push factors são preponderantes no caso dos investimentos de curto prazo em títulos.

Kim (2000) utilizou como variáveis externas para estimar os determinantes da conta capital e financeira em quatro países em desenvolvimento a taxa de juros dos títulos do Tesouro estadunidense, o PIB dos EUA e os termos de troca; como variáveis internas o autor considerou choques de demanda e de oferta. Os resultados encontrados indicam um aumento da importância dos fatores externos a partir dos anos 1980. Ou seja, a abertu-

5 Dada a indisponibilidade de dados para todos os países durante o período em questão, utilizou-se como proxy dos fluxos financeiros a variação da taxa real de câmbio e das reservas internacionais que, segundo os autores, estariam diretamente relacionados. 
ra financeira desses países intensificou a importância dos fatores externos. Em estudo semelhante, mas agora apenas para Coreia do Sul e México, Yin e Kim (2001) consideram que os ciclos de negócios dos Estados Unidos e a taxa básica de juros desse país explicam mais de 50\% dos fluxos de capitais direcionados para os países analisados entre 1980 e 1996.

Dasgupta e Ratha (2000) consideram a decisão do montante que os agentes privados globais alocarão nos países em desenvolvimento como dado e buscam estimar as variáveis internas determinantes para a escolha do destino. Os resultados encontrados sugerem que tais movimentos intensificam-se na medida em que aumenta o déficit em transações correntes, o investimento direto externo (IDE), a renda per capita e o desempenho econômico.

Mody, Taylor e Kim (2001) realizaram estimações para verificar a preponderância dos push factors ou pull factors na determinação dos fluxos de capitais privados a 32 países em desenvolvimento entre 1990 e 2000. Com base em um modelo que utiliza um vetor de correção de erros, os autores encontraram maior preponderância dos fatores internos. Outro estudo, no mesmo ano, de Hernandez, Mellado e Valdes (2001), também encontrou resultados que indicaram uma maior relevância dos fatores internos. A região do país também se mostrou relevante.

Hoti (2004) realizou diversos testes econométricos a partir de diferentes modelos teóricos e empíricos com o intuito de identificar quais seriam os fatores predominantes, push ou pull factors, na determinação dos fluxos de capitais privados. Tanto em relação aos investimentos externos diretos, como em relação aos investimentos de portfólio, encontrou-se maior evidência para os fatores externos. Todavia, o autor não descarta a importância dos pull factors, que explicariam as diferenças nos influxos de capitais entre as regiões.

Baeck (2006) verifica os determinantes dos investimentos de portfólio para 5 países latino-americanos e 4 asiáticos separadamente por região entre 1989 e 2002. Os resultados obtidos apontam para uma predominância do indicador de aversão ao risco para a Ásia, além dos demais push factors, sendo que os pull factor não se mostraram significativos. Para os países latino-americanos, tanto os push, quanto os pull factors foram significativos, sendo que a variável de aversão ao risco não se mostrou determinante.

Edison e Warnock (2008) confirmaram evidências anteriores sobre a relevância dos push factors sobre os influxos de capitais. No estudo em questão, 
as alterações na taxa de juros dos Estados Unidos e no seu desempenho econômico afetaram negativamente os influxos de capitais para os países em desenvolvimento da América Latina e Ásia. Já os pull factors mostraram-se menos relevantes, com parcial influência dos retornos dos ativos internos na América Latina e insignificância das medições de risco. Avaliando também os impactos da redução dos controles de capitais, os autores encontraram relações apenas de longo prazo e somente nos países asiáticos.

Dois estudos retomam a literatura sobre os push e pull factors sobre regiões específicas. Brana e Lahet (2010), a partir de testes sobre 4 países asiáticos durante o período de 1990 e 2007, encontraram preponderância dos primeiros fatores na determinação dos influxos de capitais, com destaque para as estratégias de carry-trade dos agentes privados globais, para a liquidez global e fatores de contágio; os fatores internos mostraram-se pouco relevantes. Já Atoyan, Jaeger e Smith (2012) realizaram testes empíricos para verificar se as políticas fiscais adotadas pelos países em desenvolvimento europeus no período 2000 a 2007 alteraram o comportamento dos fluxos privados direcionados a esses países. Os resultados apontaram para o predomínio dos push factors, sobretudo os baixos retornos nos países de origem dos fluxos. Concomitantemente, os resultados indicaram a ineficácia da política monetária em conter o excesso de influxo de capitais nos países em questão.

A partir de um painel com 46 países entre os anos de 1990 e 2007, Bruno e Shin (2013) buscam estimar os determinantes do fluxo internacional de capital bancário. Os resultados apontam que os fatores globais são mais relevantes que os fatores locais. Desse modo, em períodos em que os agentes privados globais estão mais propensos aos riscos e operam com maior nível de alavancagem, os empréstimos de bancos sediados nos países desenvolvidos tendem a migrar com maior força para os países em desenvolvimento. Como variável escolhida para proxy da alavancagem global, utilizou-se o Chicago Board Options Exchange Market Volatility Index (VIX), pois ele é um indicador de volatilidade que se encontra inversamente correlacionado com o nível da alavancagem global.

Ahmed e Zlate (2013), diferentemente da maior parte dos estudos apresentados nesta subseção, não utilizaram a metodologia push vs pull factors. A partir de um painel com 12 países latino-americanos e asiáticos entre 2002 e 2012 (dividido em dois períodos - 2002q1 a 2008q2 e 2009q3 a 2012q2), os principais resultados apontaram que: i) os diferenciais de cres- 
cimento entre os países desenvolvidos e em desenvolvimento foi significativo para o total dos fluxos de capitais privados (incluindo-se IDE) para os dois períodos tanto por Mínimos Quadrados Ordinários (MOO) quanto por Efeitos Fixos (FE na sigla em inglês), mas foi insignificante para o investimento de portfólio; ii) o diferencial de juros foi significativo apenas por MQO; e iii) VIX foi significativa para investimento de portfólio no primeiro período nos dois métodos adotados.

Por fim, Rey (2013) encontra uma correlação negativa entre o comportamento do VIX -considerado pela autora como indicador da incerteza e aversão ao risco durante os ciclos financeiros globais -e o influxo de capitais para diversas regiões em desenvolvimento entre 1990 e 2014. Essa observação é válida tanto para sua influência isolada como em conjunto com outras variáveis associadas aos push factors, como as proxys para as taxas de juros de curto prazo mundial e crescimento do PIB mundial. Além de influenciar os fluxos de capitais, os estudos cross-sections realizados apontaram para significativa influência dos ciclos financeiros globais -representados pelo VIX -nos mercados acionários, no crescimento da alavancagem do setor bancário e nos preços do setor imobiliário dos países em desenvolvimento.

O quadro 1 traz uma síntese dos trabalhos apresentados nesta seção.

Quadro 1 Resumo dos estudos empíricos apresentados

\begin{tabular}{l|l|l|l}
\hline Artigo & $\begin{array}{l}\text { Predomi- } \\
\text { nância } \\
\text { dos } \\
\text { fatores }\end{array}$ & $\begin{array}{l}\text { Principais variáveis determi- } \\
\text { nantes }\end{array}$ & Método \\
\hline $\begin{array}{l}\text { Calvo, Leiderman } \\
\text { e Reinhart (1993) }\end{array}$ & Externos & Taxa de juros dos EUA. & $\begin{array}{l}\text { Vetor autorregressivo- } \\
\text { VAR }\end{array}$ \\
\hline $\begin{array}{l}\text { Fernandez-Arias } \\
\text { (1996) }\end{array}$ & Externos & Taxa de juros externas. & $\begin{array}{l}\text { Painel: MQO e Efeitos } \\
\text { fixos }\end{array}$ \\
\hline $\begin{array}{l}\text { Chuhan, Claessens } \\
\text { e Mamingi (1993) }\end{array}$ & $\begin{array}{l}\text { Externos e } \\
\text { internos }\end{array}$ & $\begin{array}{l}\text { Taxas de juros de curto longo prazo, } \\
\text { taxa de câmbio e taxa de risco país. }\end{array}$ & $\begin{array}{l}\text { Painel: MQO e Mínimos } \\
\text { Quadrados Generalizados } \\
\text { (MQG) }\end{array}$ \\
\hline $\begin{array}{l}\text { Taylor e Sarno } \\
\text { (1997) }\end{array}$ & $\begin{array}{l}\text { Externos e } \\
\text { internos }\end{array}$ & $\begin{array}{l}\text { Taxas de juros de curto e longo } \\
\text { prazo, taxa de câmbio e taxa de } \\
\text { risco país. }\end{array}$ & $\begin{array}{l}\text { Cointegração e Modelo de } \\
\text { Correção de Erros (ECM) }\end{array}$ \\
\hline $\begin{array}{l}\text { Kim (2000) e Yin } \\
\text { e Kim (2001) }\end{array}$ & Externos & $\begin{array}{l}\text { Taxa de juros do tesouro dos EUA e } \\
\text { PIB dos EUA. }\end{array}$ & $\begin{array}{l}\text { VAR em ambos os } \\
\text { estudos }\end{array}$ \\
\hline
\end{tabular}




\begin{tabular}{|c|c|c|c|}
\hline Artigo & $\begin{array}{l}\text { Predomi- } \\
\text { nância } \\
\text { dos } \\
\text { fatores }\end{array}$ & $\begin{array}{l}\text { Principais variáveis determi- } \\
\text { nantes }\end{array}$ & Método \\
\hline $\begin{array}{l}\text { Dasgupta e Ratha } \\
(2000)\end{array}$ & Internos & $\begin{array}{l}\text { Déficit em transações correntes, } \\
\text { investimento externo direto, } \\
\text { renda per capita e desempenho } \\
\text { econômico. }\end{array}$ & Painel: Efeitos fixos (EF) \\
\hline $\begin{array}{l}\text { Mody, Taylor e Kim } \\
\text { (2001) }\end{array}$ & Internos & $\begin{array}{l}\text { IPC, crédito, dívida de CP sobre re- } \\
\text { servas, PIB industrial, taxa de juros } \\
\text { doméstica de CP, rating de crédito, } \\
\text { índice de ações. }\end{array}$ & $\begin{array}{l}\text { Vetor de Correção de } \\
\text { Erros (VEC) }\end{array}$ \\
\hline $\begin{array}{l}\text { Hernandez, Mellado } \\
\text { e Valdes (2001) }\end{array}$ & Internos & $\begin{array}{l}\text { PIB real, contas do governo, expor- } \\
\text { tações e serviço da dívida externa, } \\
\text { crédito bancário ao setor privado e } \\
\text { apreciação real da moeda. }\end{array}$ & Painel: Efeitos fixos \\
\hline Hoti (2004) & Externos & $\begin{array}{l}\text { Diversidade de variáveis relaciona- } \\
\text { das a fatores econômicos/finan- } \\
\text { ceiros e a fatores políticos/sociais, } \\
\text { estes em menor relevância. }\end{array}$ & VAR \\
\hline Baeck (2006) & Externos & $\begin{array}{l}\text { Renda internacional, índice de } \\
\text { aversão ao risco, desempenho do } \\
\text { mercado de ações estadunidenses } \\
\text { e taxa de juros do mesmo país. }\end{array}$ & Séries Temporais \\
\hline $\begin{array}{l}\text { Edison e Warnock } \\
(2008)\end{array}$ & Externos & $\begin{array}{l}\text { Taxa de juros dos Estados Unidos } \\
\text { e PIB desse país (ambos negativa- } \\
\text { mente). }\end{array}$ & Painel: Efeitos Fixos \\
\hline $\begin{array}{l}\text { Brana e Lahet } \\
(2010)\end{array}$ & Externos & $\begin{array}{l}\text { Estratégias de carry-trade, liquidez } \\
\text { global e fatores de contágio. }\end{array}$ & $\begin{array}{l}\text { Painel: EF, MQG e Método } \\
\text { dos Momentos Generali- } \\
\text { zados (MMG) }\end{array}$ \\
\hline $\begin{array}{l}\text { Atoyan, Jaeger } \\
\text { e Smith (2012) }\end{array}$ & Externos & $\begin{array}{l}\text { Rendimento dos ativos nos países } \\
\text { de origem dos investimentos. }\end{array}$ & Painel: Efeitos fixos \\
\hline Bruno e Shin (2013) & Externos & $\begin{array}{l}\text { VIX em nível e crescimento, dife- } \\
\text { rencial de crescimento econômico, } \\
\text { alavancagem local e dívida/PIB. }\end{array}$ & Painel: MQO e MMG \\
\hline $\begin{array}{l}\text { Ahmed e Zlate } \\
\text { (2013) }\end{array}$ & $\begin{array}{l}\text { Não se } \\
\text { aplica }\end{array}$ & $\begin{array}{l}\text { Diferencial de crescimento, VIX e } \\
\text { diferencial de juros. }\end{array}$ & Painel: Efeitos fixos \\
\hline Rey (2013) & Externos & $\begin{array}{l}\text { VIX, taxa de juros de curto prazo } \\
\text { mundial e crescimento do PIB } \\
\text { mundial. }\end{array}$ & Painel: Efeitos fixos \\
\hline
\end{tabular}

Fonte: Elaboração própria. 


\section{Método de análise}

O estudo empírico que será apresentado a seguir tem como foco os fluxos financeiros do balanço de pagamentos em termos líquidos, os quais foram obtidos pela soma dos investimentos de portfólio, dos derivativos e das outras contas. Esse resultado equivale à conta financeira subtraída do investimento externo direto (IED). Tal como em diversos trabalhos mencionados anteriormente, foi adotado um modelo para estimar os determinantes dos fluxos financeiros para os países em desenvolvimento, incorporando variáveis que se enquadram como push factor e como pull factor. No caso deste trabalho, a análise somente dos fluxos financeiros decorre do objetivo específico de confirmar(ou não) a influência de uma característica fundamental do sistema monetário e financeiro internacional contemporâneo - o grau de preferência pela liquidez dos agentes privados globais - na dinâmica desses fluxos. A análise dos fluxos de capitais incluindo o IED exigiria, igualmente, a consideração de um conjunto de fatores de natureza produtiva, o que foge ao escopo deste artigo.

Como determinantes externos, optou-se por: i) Chicago Board Options Exchange Market Volatility Index (VIX), indicador de volatilidade do índice S\&P500; ii) índice Dow Jones (Dow Jones Industrial Average) como proxy para a performance do mercado internacional de ações. iii) taxa de crescimento do PIB mundial em termos percentuais a preços de 2005; e iv) taxa básica de juros dos Estados Unidos (Federal Fund Rate) como proxy para taxa de juros de referência externa. Já os fatores internos adotados foram: i) taxa de juros dos depósitos dos respectivos países, como proxy para taxa de juros interna; ii) taxa de câmbio corrente como proxy para taxa de câmbio esperada; iii) produto interno bruto a preços constantes; iv) saldo em transações correntes sobre o PIB; e v) reservas totais sobre dívida externa.

Todas as variáveis são anuais ${ }^{6}$ e, a fim de reduzir a dispersão da amostra e dos erros, elas foram normalizadas ${ }^{7}$. Os símbolos das variáveis e os dados sobre a fonte e o sinal esperado são apresentados no Quadro 2.

6 O Chicago Board Options Exchange Market Volatility Index (VIX) e as três taxas de juros dos EUA foram obtidas em dados mensais e anualizado por meio de média simples dos períodos observados.

7 Adotou-se a seguinte técnica de normalização: subtração das variáveis pela média e divisão pelo desvio-padrão. 
Quadro 2 Fonte de dados e sinal esperado

\begin{tabular}{|c|c|c|c|c|}
\hline Variável & Variável por extenso & Fonte & Unidade de medida & $\begin{array}{l}\text { Sinal } \\
\text { espe- } \\
\text { rado }\end{array}$ \\
\hline fdek & Fluxos de capitais não produtivos & IFS/IMF ${ }^{1}$ & US\$ milhões corrente & \\
\hline vix & $\begin{array}{l}\text { Chicago Board Options Exchange } \\
\text { Market Volatility Index }\end{array}$ & $\mathrm{CBOE}^{2}$ & $\begin{array}{l}\text { Índice - } \\
\text { valores unitários }\end{array}$ & - \\
\hline pibmp & $\begin{array}{l}\text { Produto interno bruto mundial a } \\
\text { preços constantes }\end{array}$ & WEOD/IMF ${ }^{3}$ & Variação percentual & + \\
\hline dowjones & Índice Dow Jones & $\begin{array}{l}\text { Federal Reserve } \\
-\mathrm{BSL}^{4}\end{array}$ & $\begin{array}{l}\text { Índice - } \\
\text { valores unitários }\end{array}$ & - \\
\hline ffr & Federal Funds Rate & $\begin{array}{l}\text { Federal Reserve } \\
\text { - BSL }\end{array}$ & Taxa nominal & - \\
\hline jurosd & Taxa de juro dos depósitos & IFS/IMF & Taxa nominal & + \\
\hline cambio & Taxa nominal de câmbio & IFS/IMF & Taxa nominal & - \\
\hline pib2005 & $\begin{array}{l}\text { Produto interno bruto a preços } \\
\text { constantes }\end{array}$ & IFS/IMF & Variação percentual & + \\
\hline tc & $\begin{array}{l}\text { Saldo em transações correntes } \\
\text { sobre o PIB }\end{array}$ & IFS/IMF & $\begin{array}{l}\text { Razão de variáveis } \\
\text { originalmente em } \\
\text { US\$ milhões corrente }\end{array}$ & - \\
\hline reservas & $\begin{array}{l}\text { Reservas totais sobre a dívida } \\
\text { externa }\end{array}$ & IFS/IMF & $\begin{array}{l}\text { Razão de variáveis } \\
\text { originalmente em } \\
\text { US\$ milhões corrente }\end{array}$ & + \\
\hline
\end{tabular}

Fonte: Elaboração Própria.

Notas: (1) International Financial Statistic / International Monetary Fund; (2) Chicago Board Options Exchange; (3) World Economic Outlook Database / International Monetary Fund; (4) Federal Reserve Bank of Sant Louis.

Antes de avançar nas especificações do modelo, cabem algumas explicações adicionais sobre as variáveis escolhidas. As variáveis classificadas como push factors, vix e pibbm estão relacionadas com a questão das expectativas dos agentes internacionais; dowjones e ffr representam as alternativas de rendimento que os agentes privados globais dispõem nos países desenvolvidos. Em contrapartida, juros e cambio, refletem as possibilidades de rendimentos nos países em desenvolvimento. A variável pib2005 reflete o dinamismo da economia e as demais variáveis estão relacionadas com o grau de vulnerabilidade interna e externa dos países. Tais variáveis foram verificadas em diferentes trabalhos vistos na seção anterior.

A variável vix foi adotada porque tem sido considerada, a exemplo 
de Ahmed e Zlate (2013), Rey (2013) e Bruno e Shin (2013), a melhor representação da aversão ao risco dos agentes privados globais. Quanto maior seu nível, maior será a aversão ao risco. Em termos keynesianos, a elevação do vix poderia ser interpretada como um aumento da preferência pela liquidez, a qual resulta, devido às assimetrias do sistema monetário internacional, num movimento de aumento da demanda por títulos dos países desenvolvidos, sobretudo do governo dos Estados Unidos e, consequentemente, redução dos fluxos de capitais aos países em desenvolvimento.

Espera-se sinal negativo da variável dowjones por ela representar uma alternativa de rendimento aos investimentos nos países em desenvolvimento. $O$ crescimento mundial seria indicador de otimismo e tenderia a incentivar investimentos em mercados que ofereçam maior rentabilidade em detrimento da menor liquidez, como os mercados monetários, cambiais e financeiros dos países em desenvolvimento. Ele também deveria impactar positivamente nos fluxos de capitais por meio do efeito de acréscimo na riqueza, seja ela decorrente da elevação dos preços dos ativos negociados nos mercados acionários, seja por meio do aumento total de riqueza proporcionado pelo crescimento econômico corrente.

A utilização das variáveis jurosd e reservas é decorrente das limitações na disponibilidade de informações. No caso da primeira variável, no âmbito de todas as taxas de juros, as taxas incidentes sobre os depósitos apresentou a maior disponibilidade para os países da amostra no período analisado. Já a escolha do endividamento externo como denominador para as reservas explica-se pela falta de dados para o cálculo do passivo externo líquido para a maior parte dos países no período em questão.

Cabe ainda explicações para seleção de certas variáveis e pela não inclusão de outras. A adição de muitas variáveis tornaria excessivo o número de variáveis explicativas e, sendo assim, violaria o princípio da parcimônia e prejudicaria o poder da análise.

Em termos da variável que representa a vulnerabilidade externa, ajá utilização do endividamento externo no denominador das reservas facilitou a opçãopelavariável de transações correntes sobre o PIB em detrimento do endividamento externo sobre as exportações. Além disso, a primeira possui a vantagem de refletir tanto a questão da disponibilidade de divisa corrente, dado a necessidade em se suprir os déficits na conta corrente por meio de reservas ou fluxos financeiros, como também no passivo externo 
futuro. Ademais, as simulações apontaram significância estatística apenas para essa variável.

No que diz respeito à escolha da taxa de juros externa, utilizou-se três critérios: teóricos/analíticos, simulações com diferentes combinações de variáveis e pelo teste de multicolinearidade. $O$ teste do fator inflacionário da variância (FIV ou VIF na sigla em inglês) pelo comando vif do stata indicou forte presença de multicolinearidade (VIF > 10) entre as variáveis jgeua, jteua e dowjones, e entre ffr e jteua. A presença de multicolinearidade não afeta a consistência do modelo, mas pode fazer com que os testes de significância percam em eficiência e até mesmo pode inverter o sinal esperado. Testaram-se diferentes combinações entre as taxas de juros dos EUA e apenas a taxa básica de juros, ffr, se mostrou significativa. A significância da taxa de juros de curto prazo é condizente com o caráter de curto prazo dos fluxos de capitais contemporâneos, tal como desenvolvido na primeira seção.

Indicadores de endividamento interno e taxa de inflação são frequentemente colocados pelo mainstream economics, veículos de mídia especializados e agências de risco, ${ }^{8}$ como determinantes para influxo de capitais. Entretanto, alguns fatores levaram a sua não adoção, além da questão da parcimônia. Primeiramente, a revisão da literatura empírica não os apontou como fatores determinantes para os fluxos de capitais direcionados aos países em desenvolvimento. $\bigcirc$ mesmo ocorreu com as simulações realizadas. Posteriormente, em relação ao endividamento interno, compreende-se que ele pode ser pago pela própria moeda e não representaria um obstáculo significativo para os investidores externos. Já a influência da inflação para os agentes privados globais seria apenas indireta, pela necessidade de repasse do aumento dos preços para a taxa de câmbio, o que dificulta sua observação estatística. No caso do presente trabalho, como esta já está presente na regressão, reforça-se a possibilidade de não incluir a inflação no modelo.

Prosseguindo com o critério de parcimônia na escolha das variáveis, optou-se por não incluir algum indicador de abertura financeira. Os indicadores de abertura mais utilizados na literatura especializada são os que se baseiam no Annual Report on Exchange Arrangements and Exchange Restrictions (AREAER) 9 do FMI, a exemplo kaopen, desenvolvido inicialmente em

8 Sobre os critérios utilizados nas agências de risco, ver Canuto e Fonseca (2003) e Canuto, Santos e Porto (2004).

9 O AREAER é publicado anualmente pelo FMI e consiste na divulgação mais abrangente e 
Chin e Ito (2008). Contudo, há de se levar em conta que indicadores desse tipo não são suficientes para mensurar o grau de profundidade de inserção na globalização dos sistemas financeiros domésticos. Por exemplo, a Coreia do Sul possuiu ao longo da série histórica índices que indicam menor grau de abertura, porém os bancos estrangeiros tinham uma importante participação no mercado financeiro desse país, sendo responsáveis pela intermediação de volume significativo de capitais externos. Casos semelhantes podem ser observados na Rússia, Chile e Brasil (Chan-Lau, 2010; Conrad, 2009; Prates;Cintra, 2010; e World Development, 2011). Ou seja, os índices baseados no AREAER não captam necessariamente a intensidade da abertura financeira. Assim como as demais variáveis não incluídas no modelo explicadas acima, simulações com a adição da variável kaopen sempre apontaram para insignificância estatística da mesma.

Um último aspecto a ser levado em conta refere-se à escolha das variáveis em seus valores correntes como proxy para seus rendimentos futuros. Essa decisão se apoiou na premissa de Keynes (1937) sobre o comportamento dos agentes privados globais sob condições de incerteza. Como comentado na primeira seção, agentes econômicos entendem que o presente é um melhor guia para o futuro do que as experiências passadas e o estado existente da opinião expresso nos preços é um indicativo correto das perspectivas futuras.

A técnica de análise é a de dados em painel, ${ }^{10}$ pois permite estimar em conjunto os determinantes dos fluxos de capitais não produtivos para 42 países em desenvolvimento ${ }^{11}$ da África, das Américas, da Ásia e da Europa entre 1990 e 2008. ${ }^{12}$ Assim, optou-se pelo seguinte modelo, expresso na equação 1:

completa sobre as práticas de gestão dos fluxos de capitais utilizadas pelos países.

10 A técnica de dados em painel apresenta importantes vantagens, entre as quais: i) Permite identificar efeitos que não seriam detectados isoladamente com dados em corte transversal ou séries temporais; ii)maior número de graus de liberdade, pois ele é resultado do produto dos graus de liberdade das unidades de corte transversal e de série temporal, o que é especialmente importante quando a fonte está apenas em dados anuais; e iii) permite evitar vieses associados a fatores individuais e/ou temporais não observáveis, o que em uma regressão normal seria diluído na média. 11 Os países utilizados são: África do Sul, Argentina, Bolívia, Botsuana, Brasil, Bulgária, Chile, China, Colômbia, Coréia do Sul, Costa do Marfim, Costa Rica, Egito, El Salvador, Equador, Eslovênia, Filipinas, Hungria, Ilhas Maurício, Índia, Indonésia, Jordânia, Kuwait, Malásia, Marrocos, México, Nigéria, Panamá, Paquistão, Paraguai, Peru, Polônia, Romênia, Rússia, Singapura, República Tcheca, Sri Lanka, Tailândia, Turquia, Ucrânia, Uruguai e Zâmbia.

12 O corte para escolha dos países se deu quando não havia a disponibilidade de dados para pelo menos duas variáveis ou que fossem disponíveis em menos da metade do período. A escolha do período inicial se deu com base no momento em que os países em desenvolvimento se reinseriram no processo de globalização financeira até a ocorrência da crise financeira global. 


$$
\begin{aligned}
& \text { fdek }_{i t}=\beta_{0}+\beta_{1} \text { vix }_{t}+\beta_{2} \text { dowjones }_{\mathrm{t}}+\beta_{3} \text { pibmp }_{\mathrm{t}}+\beta_{4} \mathrm{ffr}_{\mathrm{t}}+ \\
& \beta_{5} \text { jurosd }_{\mathrm{it}}+\beta_{6} \text { cambio }_{\mathrm{it}}+\beta_{7} \text { pib2005 }_{\mathrm{it}}+\beta_{8} \mathrm{tc}_{\mathrm{it}}+\beta_{9} \text { reservas }_{i t}+e_{i t}
\end{aligned}
$$

Em que o subscrito i denota os diferentes indivíduos, no caso países, e o subscrito $t$ indica o período de tempo observado, no caso ano. $\beta_{0}$ refere-se ao parâmetro de intercepto e $\beta_{\mathrm{k}}$ ao coeficiente angular da k-ésima variável explicativa do modelo. Por fim, eit representa o termo do erro aleatório do i-ésimo individuo (país) no t-ésimo período (ano). As variáveis tratadas como push factors não são acompanhadas pelo subscrito i, pois elas não variam entre os países.

Entretanto, parcela significativa das heterogeneidades dos erros não está associada apenas aos regressores, mas também a variáveis não observáveis relacionadas às características dos indivíduos. Quando isso ocorre, na utilização do Modelo Clássico de Regressão Linear (MCRL), o pressuposto necessário de não correlação entre os regressores e o erro será violado. Formalmente: se a correlação entre c e xj, em que j denota determinado indivíduo, for positiva, a estimação da equação 1 seria viesada e os resultados seriam inconsistentes. ${ }^{13}$

Três técnicas mais tradicionais podem ser utilizadas para solucionar os problemas das heterogeneidades individuais. Uma delas é controlar os efeitos não observados correlacionados às variáveis independentes por meio dos efeitos fixos com a utilização de estimadores de variáveis binárias. Uma segunda técnica se dá por meio do modelo com efeitos aleatórios, o qual parte do princípio de que os interceptos variam de forma aleatória e não devido a características específicas dos indivíduos. Além do mais, pressupõe que os erros do modelo relacionados às variáveis não observáveis não são correlacionados com as variáveis independentes. A terceira é por meio das regressões em primeira diferença, já que os efeitos das variáveis explicadas refletem apenas um período para outro, pois o que se estima é o impacto da variação da variável independente sobre a variação da variável explicada.

Há um limite na base de dados disponibilizada pelo FMI no que se refere à escolha de dados dos balanços de pagamentos. Para dados posteriores a 2008, a série se inicia apenas em 2002.

13 No evento de variáveis omitidas, algo provável de ocorrer em modelos econométricos, pode-se se expressar a relação entre y e $\mathrm{x}$ da seguinte forma: $y=\mathrm{x}_{\mathrm{t}} \beta+c+e$. Nessa equação, caso $c$ não esteja correlacionado com as variáveis independentes $(\mathrm{x})$, então ele será apenas um dos fatores não observáveis que compõem o erro da regressão (e). Portanto, a utilização do modelo de $\mathrm{MQO}$ aplicado a painel seria válida. Neste caso, se manteria a equação 1. 
Outros problemas que merecem atenção são a heterocedasticidade, a autocorrelação, a endogeneidade e a suposição da exogeneidade estrita. Os dois primeiros problemas já são bastante conhecidos. Para ambos os parâmetros do modelo $\mathrm{MQO}$ se mantêm consistentes e não viesados, mas deixam de ser eficientes e as estimativas dos erros padrão se tornam viesadas. Qualquer um dos modelos acima mencionados possuem ferramentas para corrigir a variância dos estimadores, tornando-os robustos à quebra da homocedasticidade e da autocorrelação.

Quanto à endogeneidade, ela significa que há uma relação entre os resíduos e as variáveis independentes, devido à determinação simultânea entre as variáveis explicativas e explicada. Nesse caso, os estimadores MQO são viesados e inconsistentes. Por fim, resta a questão da necessidade em se respeitar a validade da hipótese de exogeneidade estrita para que a regressão não incorra em resultados inconsistentes. Esta é uma hipótese bastante restritiva e implica que todas as variáveis explanatórias de um modelo não podem ser correlacionadas com erro, não apenas no presente, como também no passado e no futuro. Ou seja, as variáveis passadas não podem afetar os erros e estes não podem afetar o futuro das variáveis explicativas (Wooldridge, 2007).

Felizmente, existem dois procedimentos de estimação que conseguem resolver todas essas questões levantadas. São os modelos baseados no Método dos Momentos Generalizados (MMG) desenvolvido inicialmente por Arellano e Bond (1991). Ele resolve o problema da endogeneidade e permite relaxar a hipótese da exogeneidade estrita porque define condições de momentos a partir de valores defasados das variáveis dependentes ou outras variáveis exógenas definidas como instrumentos. Tais instrumentos são por suposição não correlacionados com o termo de erro da regressão (Roodman, 2009).

Para controlar o problema das variáveis não observáveis, Arellano e Bond propõem realizar regressões transformando as variáveis originais em primeira diferença, este método ficou conhecido como Método dos Momentos Generalizado-Diferenciados (MMG-D). Contudo, como demonstram Arellano e Bover (1995) e Blundell e Bond (1998), este método possui limitações quando o comportamento da variável dependente se aproxima de um passeio aleatório. Isso porque o $M M G$ não seria eficiente, já que nesse caso os valores passados teriam pouco a dizer sobre o futuro. Caso o período observado seja reduzido, os estimadores podem ser viesados. 
Com o intuito de aprimorar a eficiência do MMG, esses autores propõem um método mais eficiente e que não traz os problemas mencionados. Ao invés de transformar os regressores em primeira diferença para expurgar os efeitos fixos, mantém as variáveis em nível como regressores, mas combina com as respectivas variáveis em diferença defasadas na forma de instrumentos, os quais não são, por definição, correlacionados com os efeitos fixos. Esse método é conhecido como método dos momentos generalizados-sistema (MMG-S). Por não apresentar as limitações do MMG-D, ele será adotado nas estimações deste trabalho. A equação geral desse modelo pode ser representada de acordo com a equação 2 abaixo:

$$
y_{i t}=\beta_{1}^{T} w_{1 i t}+\beta_{2}{ }^{T} w_{2 i t}+c i_{i}+c t_{t}+e_{i t}
$$

Na qual o $w_{1 i t}$ é um vetor transposto (indicado pelo sobrescrito $\mathrm{T}$ ) em que seriam incluídas as variáveis com suspeita de endogeneidade (passada, presente ou futura); $\mathrm{w}_{2 \mathrm{it}}$ é um vetor que incluiria as variáveis consideradas como estritamente exógenas; ci $_{1}$ são as binárias para os indivíduos e ctt são as binárias para os anos. A partir das variáveis desse vetor é que seriam retirados os instrumentos. Na equação aqui adotada, as variáveis classificadas como pull factors foram incluídas em w1it e as push factors em $\mathrm{w}_{2 \mathrm{it}}$.

Para que o modelo MMG-S seja consistente, faz-se necessário o atendimento de duas suposições. Uma se refere a não correlação dos erros. Arellano e Bond (1991) desenvolvem testes baseados em erros transformados por primeira diferença para verificar a presença de correlação dos erros. Devido a essa característica, é esperado que seja autocorrelacionado de primeira ordem. Esse modelo aceita autocorrelação desta ordem, mas autocorrelação de segunda ordem, AR (2), indicaria inconsistência do modelo.

A segunda suposição está relacionada com a adequação na escolha dos instrumentos. Para verificação dessa suposição, a regressão com base no MMG-S realiza o teste da estatística J de Hansen, que é uma versão robusta à quebra de heterocedasticidade e presença de autocorrelação do teste de restrição sobre identificação de Sargan. Ele adota como hipótese nula que os instrumentos são adequados ao modelo de MMG, isto é, se eles são de fato estritamente exógenos. Adicionalmente, são reportados os testes de diferenças nos testes Hansen para exogeneidade do grupo de instrumentos.

Uma observação importante a ser feita se refere ao problema da utilização de um número elevado de instrumentos relativamente ao total de 
variáveis cross-sections (no caso países). Conforme argumenta (Roodman, 2009), quando em um painel, $T$, for superior a 3, existe a tendência de ocorrer um excesso de instrumentos, o qual pode provocar superestimação nos coeficientes das variáveis endógenas utilizadas como instrumentos. Isso faz com que a regressão se distancie dramaticamente do que seria assintoticamente ideal. Além do mais, o teste de Hansem é sensível ao número relativamente demasiado de instrumentos, pois gera p-valores inverossímeis. Para evitar a proliferação de instrumentos, o aplicativo Stata 12 oferece uma função que impede que os instrumentos se espalhem, por meio de uma matriz de instrumentos acachapada. Para tal, foi utilizada a sub opção colapse $e^{14}$ disponível para a regressão com o comando $x$ tabond $2^{15}$.

Por fim, resta esclarecer que se utilizou a estimação por meio do two-step ao invés de one-step, pelo fato do primeiro produzir coeficientes mais eficientes, com viés de baixa e menor erro-padrão. Esse estimador é, por definição, robusto e eficiente à presença de heterocedasticidade e autocorrelação. Contudo, o respectivo estimador das variâncias pode subestimar as reais variâncias. Para corrigir esse problema fez-se uso do método proposto por Windmeijer (2005), cujo comando no stata é a subopção robust. ${ }^{16}$

\section{Análise dos resultados}

Os resultados do modelo MMG-S são apresentados na tabela 1. Contudo, antes de prosseguir com a análise dos resultados, faz-se necessário avaliar os testes de consistência do modelo. $O$ teste da estatística J de Hansen apontou que $\mathrm{H} 0$ não pode ser rejeitada, o que valida os instrumentos utilizados. Também são reportados os testes de diferenças nos testes Hansen para exogeneidade do grupo de instrumentos, todos os quatro testes

14 Nos comentários da tabela 1 encontra-se o número de instrumentos com a utilização do comando colapse, que são 20. Sem a utilização deste comando, há uma proliferação de instrumentos (240) que os torna numericamente muito maior do que o total de variáveis cross-sections (42). Ademais, todos os testes apontaram para inadequação dos instrumentos (Teste Hansen excluindo grupo: qui ${ }^{2}(150)=603,81$, Prob > qui2 $=0,000$; Diferença $\left(\mathrm{H}_{0}=\right.$ exógenos): qui ${ }^{2}(80)=6986,14$ Prob $>$ qui $\left.^{2}=0,000\right)$, ao contrário do que ocorre quando se utiliza o comando colapse, tal como será observado na seção 4.

15 Ver Roadman (2009) sobre as especificações, recomendações e vantagens em se utilizar o comando xtabond2 para realizar regressões pelo método MMG-S.

16 Quando se utiliza os estimadores one-step, a subopção robust tem o sentido de tornar os estimadores robustos à heterocedasticidade e homocedasticidade. 
apresentados indicam adequação tanto dos instrumentos sob suspeita de quebra de exogeneidade estrita como também para o subgrupo de instrumentos classificados como estritamente exógenos. Já os testes de autocorrelação apresentados não apontaram para presença de autocorreção, pois, tanto o de primeira ordem quanto o de segunda ordem apresentaram estatísticas não significativas. Destarte, a consistência do modelo é reafirmada.

Tabela 1 Regressão por MMG ajustada

\begin{tabular}{lrrr}
\hline Variável & Coeficiente & Erro-padrão & Prob. > t \\
\hline vix & $-0,1004$ & 0,0474 & 0,042 \\
\hline dowjones & $-0,1203$ & 0,0519 & 0,027 \\
\hline pibmp & 0,0748 & 0,0355 & 0,043 \\
\hline ffr & $-0,1848$ & 0,0879 & 0,044 \\
\hline jurosd & $-0,4563$ & 0,7199 & 0,531 \\
\hline cambio & $1,84 \mathrm{E}-05$ & $1,36 \mathrm{E}-05$ & 0,186 \\
\hline pib2005 & $-0,0298$ & 0,0705 & 0,676 \\
\hline tc & $-8,1878$ & 2,1684 & 0,001 \\
\hline reservas & 0,0858 & 0,0597 & 0,16 \\
\hline constante & 0,3471 & 0,1026 & 0,002 \\
\hline
\end{tabular}

Fonte: elaboração própria a partir de resultados obtidos no Stata 12.

Número de observações: 546. Número de países: 42.

Número de instrumentos: 20

Teste F: Prob. $=0,000$

$A R(2):$ Prob. $=0,505$

Hansen: Prob. $=0,915$

Hansen em Diferença: Prob.0,853

Analisando a tabela 1, observa-se que as quatro variáveis utilizadas como push-factors, vix, dowjones, pibmp e ffr foram estatisticamente significativa a $5 \%$ e tiveram sinal como esperado. Em contrapartida, das variáveis classificadas como pull-factors, apenas o saldo em transações sobre o PIB, variável $t c$, mostrou-se significativo, também a $5 \%$ e dentro do sinal esperado. Nenhuma das variáveis que indicariam o retorno para o investidor, juros e cambio, se mostraram significativas. Esses resultados vão ao encontro de diversos trabalhos apresentados na segunda seção em que há uma predominância dos fatores externos sobre internos.

Merece especial atenção a corroboração do Indicador de Volatilidade VIX; a significância estatística do rendimento dos países desenvolvidos, re- 
presentado pelos EUA, e a não significância dos rendimentos domésticos; além do fato do desempenho da economia mundial ter sido significativo enquanto o desempenho doméstico não o foi.

\subsection{Resultados das regressões com associação das variáveis contí- nuas com a dummy para crise}

Conforme observado na seção anterior, das variáveis classificadas como pull factors, apenas a variável tc se mostrou estatisticamente significativa. Porém, embora elas não tenham apresentado significância estatística na atração dos fluxos financeiros internacionais para os países em desenvolvimento, elas podem influenciar no comportamento dos mesmos nos momentos de crise. Nesta subseção, especificamente, objetiva-se verificar se a variável reservas serve de atenuante para os fluxos líquidos de capital nos momentos de crise. Essa averiguação seria importante para referendar, ou não, as estratégias defensivas de acúmulo de reservas feitas por diversos países emergentes principalmente durante a década de $2000 .{ }^{17}$ Para verificar se isso ocorre foi incluída no modelo uma dummy para crises financeiras, denominada como crise, e se relacionará com as variáveis contínuas.

A dummy abrange os seguintes anos: 1994, 1997, 1998, 1999, 2002 e 2008. A escolha se deu com base nos períodos de maior reversão nos fluxos de capitais, os quais foram decorrentes pelas crises dos países em desenvolvimento e o último da crise financeira global. Essa dummy não fora acrescentada no modelo anterior por não ter sido significativa. Além disso, houve uma piora nos desvios-padrão e nos coeficientes, tendo baixa alteração nas significâncias estatísticas das demais variáveis. Todavia, ela pode apresentar significância estatística se associada a outras variáveis, seguindo a mesma lógica das variáveis não significativas que podem passar a ser quando associadas com essa dummy.

O método adotado para encontrar a relação entre as variáveis contínuas e a dummy para as crises originou-se comas duas variáveis pull factors apresentados na tabela 1 que estão relacionadas com a vulnerabilidade interna/ externa do país: tc e reservas. A relação da dummy com variável contínua não é possível de ser realizada pelo método GMM. Optou-se, então, pelos 
modelos de efeitos fixos (FE) e aleatórios (RE) robustos à heterocedasticidade e autocorrelação, cujas equações são respectivamente:

$$
\begin{aligned}
& \mathrm{fdek}_{\mathrm{it}}=\beta_{0}+\beta_{1} \text { vix }_{\mathrm{t}}+\beta_{2} \text { dowjones }_{\mathrm{t}}+\beta_{3} \text { pibmp }_{\mathrm{t}}+\beta_{4} \mathrm{ffr}_{\mathrm{t}}+\beta_{5} \text { jurosd }_{\mathrm{it}} \\
& +\beta_{6} \text { cambio }_{\mathrm{it}}+\beta_{7} \text { pib2005 }_{\mathrm{it}} \beta_{8} \mathrm{tc}_{\mathrm{it}}+\beta_{9} \text { reservas }_{\mathrm{it}}+\sum_{i=1}^{t} \delta_{i} \text { dummy } x \beta \text { Xit } \\
& +c_{2} \mathrm{I}_{2 \mathrm{i}}+\ldots+c_{\mathrm{n}} \mathrm{I}_{\mathrm{ni}}+e_{i t}
\end{aligned}
$$

A equação (3) traz como novidade em relação à equação (1) a inclusão de estimadores de variáveis binárias, cj. Além disso, o intercepto $\beta_{0}$ altera seu significado usual e passa a referir o efeito para o indivíduo utilizado como referência. Já na equação (4), $c_{i}$ representa as oscilações aleatórias em torno de um valor médio constante $\left(\beta_{0}\right)$. Em comum, ambas as equações acrescentam a relação entre a dummy e as variáveis explicativas classificadas como pull factors $\left(\sum_{i=1}^{t} \delta_{i}\right.$ dummy $x \beta$ Xit $)$.

A escolha de qual modelo adotar se deu com base no teste Hausman. Este teste verifica se os resultados apresentados pelos dois métodos são significativamente distintos. Caso não o sejam, poder-se-ia adotar o modelo de efeitos aleatórios, mais eficiente. Sendo distintos, optar-se-ia pelos efeitos fixos, pois haveria indício de inconsistência nos estimadores. Os resultados sugerem, com $100 \%$ de chance de estar errado, rejeição da hipótese $\mathrm{HO}$ de diferença nos coeficientes não sistemática. Ou seja, não se pode rejeitar $\mathrm{HO}$ e, portanto, a opção por efeitos aleatórios se mostra a mais adequada.

Porém, antes de prosseguir para os resultados, deve-se ainda verificar a validade da hipótese de exogeneidade estrita para que as regressões por efeitos aleatórios não incorram em resultados inconsistentes.De acordo com Wooldridge (2007), existem dois testes para se verificar a quebra da hipótese da exogeneidade estrita. Um deles é realizar a regressão por meio de efeitos fixos e depois compará-la com a regressão em primeira diferença. Entretanto, para regressões com t $>$ 2, Wooldridge (2007, p. 285) recomenda o teste com basena seguinte equação: 


$$
y i t=\beta X i t+\delta W i t+1+c i+e i t
$$

Essa equação (5) é equivalente à equação de efeitos fixos em que se acrescenta um vetor $(\delta \mathrm{Wit}+1)$ contendo um subconjunto dos regressores originais ( $\beta$ Xit), mas em $t+1$. A hipótese nula é que $\delta=0$; desse modo, a hipótese de exogeneidade estrita se mantém e poder-se-ia prosseguir com as estimações com base no modelo de efeitos fixos. $O$ subconjunto $t+1$ da equação 3 deverá conter todas as variáveis sob suspeita de ausência de exogeneidade estrita. Neste trabalho se colocou todas as variáveis classificadas como pull factors. ${ }^{18}$ Nenhuma variável testada apresentou indícios de quebra da hipótese de exogeneidade estrita. Ou seja, não pode se rejeitar H0 (ver apêndice 1). Sendo assim, segue-se com o modelo por efeitos aleatórios, cujos resultados se encontram na tabela $2 .{ }^{19}$

Tabela 2 Resumo das regressões por RE: dummy x (reservas, tc)

\begin{tabular}{lrrr}
\hline Variável & Coeficiente & Erro-padrão & Prob. $>$ t \\
\hline vix & $-0,0719$ & 0,0339 & 0,034 \\
\hline dowjones & $-0,1521$ & 0,0769 & 0,048 \\
\hline pibmp & 0,1213 & 0,0694 & 0,08 \\
\hline ffr & $-0,1052$ & 0,0805 & 0,191 \\
\hline pib2005 & $-0,0308$ & 0,1377 & 0,823 \\
\hline jurosd & $-0,0038$ & 0,0037 & 0,303 \\
\hline cambio & $-0,0001$ & 0,0001 & 0,986 \\
\hline crise & 0,0462 & 0,0568 & 0,416 \\
\hline tc & $-3,553$ & 1,7151 & 0,038 \\
\hline tc* ${ }^{*}$ crise & $-3,0317$ & 1,5899 & 0,057 \\
\hline reservas & $-0,0029828$ & 0,0235 & 0,899 \\
\hline reservas ${ }^{*}$ crise & 0,0883266 & 0,0306 & 0,004 \\
\hline constante & 0,1778 & 0,1011 & 0,079 \\
\hline
\end{tabular}

Fonte: elaboração própria a partir de resultados obtidos no Stata 12.

18 Foram incluídos nos testes de exogeneidade estrita variáveis em que foram realizadas simulações mas que não foram incluídas na equação definitiva.

19 O leitor atento poderia indagar por que não utilizar o modelo RE no lugar do MMG-S, já que os testes indicaram consistência na utilização do primeiro modelo. O motivo se deve principalmente pelo critério de parcimônia na decisão de qual modelo utilizar. Enquanto no modelo RE precisam ser realizados testes para verificação de que a suposição de exogeneidade não está sendo violada, no modelo MMG-S, essa suposição pode ser relaxada. Ademais, o modelo MMG-S two step é, por definição, robusto e eficiente à heterocedasticidade e autocorrelação. 
Os dados reportam a significância estatística das combinações entre a dummy para crise com as variáveis reservas, a $5 \%$ de significância, positivamente, e tc a $10 \%$, negativamente. $O$ significado desses resultados é que, em momentos de crise, as reservas internacionais podem servir como atenuante. Já o déficit em transações correntes, além de afetar negativamente os fluxos de capitais ao longo do tempo, tem seu efeito negativo reforçado em momentos de crise. Embora não seja o foco dessa regressão, cabe ressaltar que mesmo nesse modelo em que há perda de graus de liberdade, as variáveis vix e dowjones mantiveram-se estatisticamente significativas a $5 \%$.

Além de tc e reservas, foram testadas outras variáveis cuja não inclusão na equação 1 fora justificada na seção 3 e que também estão relacionadas com a vulnerabilidade interna/externa do país, quais sejam: taxa de inflação, endividamento interno sobre o PIB e dívida externa sobre exportações. Como em nenhuma combinação elas foram significativas ao se relacionarem com a dummy para crise, os resultados não foram reportados.

\section{Considerações finais}

Keynes (1983) mostrou como agentes privados racionais adotam comportamentos convencionais em condições de incerteza numa economia fechada. A atualização da sua análise para uma economia aberta após o colapso do sistema de Bretton Woods fornece uma explicação para a dinâmica volátil dos fluxos de capitais no SMI contemporâneo. As características do SMI contemporâneo (dólar fiduciário, regime de câmbio flutuante e livre mobilidade de capitais) resultam numa incerteza estrutural em relação à evolução dos preços-chave da economia internacional (taxas de juros e de câmbio da divisa-chave). Nesse contexto, são frequentes as variações no grau de preferência pela liquidez dos agentes privados, que, consequentemente se comportam de forma mimética, o que implica alta instabilidade nos fluxos de capitais internacionais. Todavia, essa instabilidade é ainda mais acentuada no caso dos fluxos direcionados aos países em desenvolvimento devido às assimetrias do SMFI contemporâneo. Como as moedas desses países não exercem as suas funções clássicas em âmbito internacional, em momentos de incerteza e elevação da preferência pela liquidez, os capitais se direcionam para o país emissor da moeda-chave do sistema e, em menor grau, para os demais países centrais. Por conseguinte, os ca- 
pitais podem sair dos países em desenvolvimento mesmo que não haja deterioração nos fundamentos econômicos domésticos.

Os testes econométricos realizados corroboraram vários aspectos destacados pela interpretação pós-keynesiana sintetizada. O primeiro deles se refere à relação entre o grau de preferência por liquidez e a demanda por ativos dos países emissores de moedas periféricas. A variável vix, utilizada como proxy para medir o grau de preferência global, se mostrou significativa conforme o esperado pela abordagem adotada. Ainda em relação às expectativas, o crescimento do PIB mundial, o qual tende a elevar o otimismo dos agentes privados globais, também se mostrou significativo. Destarte, os resultados indicam que os fluxos de capitais para esse grupo de países possui um caráter mais especulativo e dependente da disposição ao risco desses agentes.

Outro aspecto diz respeito à significância estatística da taxa de juros do país emissor de moeda-chave. O comportamento da taxa básica de juros dos EUA apresentou uma relação inversa aos fluxos direcionados para os países em desenvolvimento. De forma análoga, a expectativa do desempenho do mercado acionário dos países desenvolvidos, cuja Proxy utilizada foi o índice Dowjones, também se mostrou estatisticamente significativa e com impactos negativos aos fluxos de capitais para os países em desenvolvimento.

Interessante observar que as variáveis internas do PIB e a taxa de juros não se mostraram marcantes. Em relação aos indicadores de solidez econômica, apenas o déficit em transações foi significativo. Essa combinação de variáveis exógenas serem estatisticamente importantes e as variáveis internas não o serem, corrobora o argumento dos determinantes externos se sobrepujarem aos internos.

Também se realizaram regressões para verificar quais variáveis classificadas como pull-factors, em combinação com a dummy para as crises, afetariam a variável dependente. Após sucessivos testes, constatou-se que nos momentos de crise a única variável significativa ao comportamento negativo dos fluxos de capitais para os países em desenvolvimento foi a tc, já a variável reservas serve de atenuante para as saídas dos capitais nos momentos de crise. Esse resultado não é suficiente para referendar a política de acúmulo de reservas como um todo, algo que foge ao escopo do presente trabalho. Contudo, ele aponta para a adequação dessa estratégia no que tange ao objetivo de amenizar as saídas líquidas dos fluxos de capitais em momentos de crise. 
Ao se comparar com os trabalhos comentados na seção 1, os resultados encontrados neste artigo mostraram-se semelhantes aos obtidos por Taylor e Sarno (1997), Hoti (2004), Baeck (2006), Edison e Warnock (2008), Brana e Lahet (2010), Atoyan, Jaeger e Smith (2012), Bruno e Shin (2013) e Ahmed e Zlate (2013), no sentido de ter encontrado significância estatística tanto dos push quanto dos pull factors, mas com predominância dos primeiros sobre os segundos.

Deve-se, por fim, assinalar que a obtenção de resultados estatisticamente significativos para a variável VIX, proxy da aversão ao risco e da preferência pela liquidez em âmbito global, corroborou os resultados obtidos pelos trabalhos de Bruno e Shin (2013), Ahmed e Zlate (2013) e Rey (2013), sendo que os primeiros encontraram significância dessa variável para os fluxos de empréstimos internacionais (incluídos na subconta outros investimentos) e os segundos apenas para a subconta investimento de portfólio, sendo que para a conta financeira como um todo se mostrou insignificante. Este artigo, além de utilizá-la como variável determinante para a soma das duas subcontas com a de derivativos, fez regressões com diferentes variáveis de controle. Assim, esse resultado sugere que o grau de preferência pela liquidez dos investidores constitui um importante determinante da dinâmica dos fluxos financeiros no sistema monetário e financeiro internacional contemporâneo.

Como objetivo de pesquisa futura, aspira-se realizar estimações para o período pós-crise, visando comparar se houve mudanças nos determinantes dos fluxos de capitais direcionados para os países em desenvolvimento. Pretende-se ainda testar diferentes novas combinações de variáveis explicativas.

\section{Referências}

AHMED, S.; ZLATE, A. Capital flows to emerging market economies: a brave new world? Board of governors of the federal reserve system. International Finance Discussion Papers Number 1081. June 2013. Disponível em: http://www.federalreserve.gov.

AIZENMAN, J.; GLICK, R. Asset Class Diversification and Delegation of Responsibilities between Central Banks and Sovereign Wealth Funds. NBER Working Paper No. 16392 Issued in September, 2010.

AIZENMAN, J.; LEE, Y. Financial Versus Monetary Mercantilism-Long-run View of Large International Reserves Hoarding. NBER Working Papers 12718, National Bureau of Economic Research, Inc. 2006. 
AMADO, A. M. Minsky e o ciclo econômico: uma análise para economias periféricas. In: Encontro de Economia Política, 8, Florianópolis. Anais. Florianópolis: Sociedade Brasileira de Economia Política, 2003.

ANDRADE, R.; PRATES, D. M. Dinâmica da taxa de câmbio em uma economia monetária periférica: uma abordagem Keynesiana. Nova Economia, v. 22, p. 235-257, 2012.

ARELLANO, M.; BOND, S. Some tests of specification for panel data: Monte Carlo evidence and an application to employment equations. Review of Economic Studies, n.58, p. 277-97, 1991.

ARELLANO, M.;BOVER, O. Another look at the instrumental variable estimation of error-components models. Journal of Econometrics, n. 68, p. 29-51, 1995.

ATOYAN, R.; JAEGER A.; SMITH, D. The Pre-Crisis Capital Flow Surge to Emerging Europe: Did Countercyclical Fiscal Policy Make a Difference? IMF Working Paper 7. 2012. Disponível em: http://www.imf.org.

BAECK, I. M. Portfólio investment flows to Asia and Latin America: Pull, push or market sentiment? Journal of Asian Economics, n. 17, p.363-373, 2006. Disponível em: http://www. ideas.repec.org.

BELLUZZO, L. G. O dinheiro e as metamorfoses da riqueza. In: FIORI, J. L. Poder e Dinheiro. Rio de Janeiro: Vozes, 1997.

BIANCARELI, A. M. Países emergentes e ciclos internacionais. In: CARNEIRO, Ricardo de Medeiros. (Org.). A supremacia dos mercados e a política econômica do Governo Lula. São Paulo: Editora Unesp, 2006, p. 97-129.

BLUNDELL, R.; BOND, S. Initial conditions and moment restrictions in dynamic panel data models. Journal of Econometrics, n. 87, p. 115-143, 1998.

BRANA, S. D.; LAHET, D. Determinants of capital inflows into Asia: the relevance of contagion effects as push factors. Emerging Markets Review, n.11, 2010, 273-284. Disponível em: www.sciencedirect.com/science/article.

BRUNO, V.; SHIN, H. S. Capital flows, cross-border banking and global liquidity. NBER Working Paper Series, 2013.

CALVO, G.; LEIDERMAN, L.; REINHART, C. Capital flows and real exchange rate appreciation in Latin America: the role of external factors. IMF Staff Papers, vol. 40, 1993, p. 123-139.

CANUTO, O.; FONSECA, P. Risco soberano e prêmios de risco em economias emergentes. Revista Brasileira de Comércio Exterior. Ed 78. Set. 2003.

CANUTO, O.; SANTOS, P. F. P.; PORTO, P. C. S. Macroeconomics and Sovereign Risk Ratings. World Bank. Washington, January, 2004.

CHAN-LAU, J. A. The Global Financial Crisis and its Impact on the Chilean Banking System. IMF Working Paper. WP/10/108. April 2010. Disponível em: http://www.imf.org.

CHESNAIS, F. La modialisation du capital. Paris: Syros, 1994.

CHUHAN, P.; CLAESSENS, S.; MAMINGI, N. Equity and Bond Flows to Asia and Latin America. The World Bank, Policy Research Working Papers, n. 1160. 1993. Disponível em: http://www-wds.worldbank.org/. 
CINTRA, M. A.; PRATES, D. M. Os fluxos de capitais para o Brasil nos anos 1990. In: LACERDA, Antonio Correa de. (Org.). Crise e Oportunidade: o Brasil e o Cenário internacional. São Paulo: Sobeet e Editora Lazuli, 2006.

CONRAD, J. Russia in the financial crisis and beyond. DEUTSCHE BANK RESEARCH. Dec. 2009. Disponível em: http://www.dbresearch.com.

DASGUPTA, D.; RATHA, D. What Factors Appear to Drive Private Capital Flows to Developing Countries? And How Does Official Lending Respond? The World Bank, Policy Research Working Papers, n. 2392. 2000. Disponível em: http://elibrary.worldbank.org/doi/ book/10.1596/1813-9450-2392.

DAVIDSON, P. Rational Expectations: A Fallacious Foundation for Studying Crucial Decision-Making Processes. Journal of Post Keynesian Economics, v.5, n. 2 (Winter 1983), p. $182-$ 198. Disponível em: http://www.jstor.org/stable/4537730.

DEQUECH, D. Fundamental uncertainty and ambiguity. Eastern Economic Journal, v. 26, n. 1, Winter, 2000.

DOW, S. C. Money and the economic process. Aldershot, Edward Elgar, 1993.

EDISON, H. J.; WARNOCK, F. E. Cross-border listings, capital controls, and equity flows to emerging markets. Journal of International Money and Finance, Elsevier, v. 27, n.6, p. 10131027, October, 2008

FERNANDEZ-ARIAS, E. The new wave of private capital inflows: Push or pull? Journal of Development Economics, Elsevier, v. 48, n.2, p. 389-418, March, 1996.

HERNANDEZ, L.; MELLADO, P.; VALDEZ, R. Determinants of Private Capital Flows in the 1970s and 1990s: Is There Evidence of Contagion? IMF Working Paper, N. 01/64. 2001. Disponível em: http://www.imf.org.

HOTI, S. An empirical evaluation of international capital flows for developing countries. Mathematics and computers in simulation, v. 64, 2004.

ISARD, P. Globalization and the International Financial System. Cambridge: Cambridge University Press, 2005.

KEYNES, J. M. The general theory of employment. The Quarterly Journal of Economics, February, 1937.

KEYNES, J. M. A teoria geral do emprego do juro e do dinheiro. Coleção Os economistas. São Paulo: Editora Abril, 1983.

KIM, Y. Causes of Capital Flows in Developing Countries. Journal of International Money and Finance, v.19. 2000. Disponível em: http://www.sciencedirect.com.

MODY, A; TAYLOR, M. P.; KIM, J. Y. Modeling Fundamentals for Forecasting Capital Flows to Emerging Markets. International Journal of Finance and Economics, v.6. 2001. Disponível em: http://www.amody.com/pdf/forecasting.pdf.

PRATES, D. M. A abertura financeira dos países periféricos e os determinantes dos fluxos de capitais. Revista de Economia Política, São Paulo, v. 19, 1999.

PRATES, D. M. Crises financeiras dos países "emergentes": uma interpretação heterodoxa. Tese (Doutorado em Economia), Instituto de Economia, Universidade Estadual de Campinas, Campinas, 2002. 
PRATES, D. M. As assimetrias do sistema monetário e financeiro internacional. Revista de Economia Contemporânea, Rio de Janeiro, mai/ago, v. 9, n. 2, p. 263-288, 2005.

PRATES, D. M.; CINTRA, M. A. M. The Emerging-market Economies in the Face of the Global Financial Crisis. In: DULLIEN, Sebastian; KOTTE, Detlef J.; MÁRQUEZ, Alejandro; PRIEWE, Jan. (Org.). The Financial and economic crisis of 2008-2009 and developing countries. New York and Geneva: United Nations, 2010, p. 53-71.

REY, H. Dilemma not Trilemma: The Global Financial Cycle and Monetary Policy Independence. London Business School, CEPR and NBER August, 2013.

ROODMAN, D. How to do xtabond2: an introduction to difference and system GMM in Stata. Stata Journal, v.9, n.1, p.86-136, 2009. Disponível em: http://www.stata-journal. com/article.html?article $=$ st 0159 .

SERRANO, F. Do ouro imóvel ao dólar flexível. Economia e Sociedade, v. 11, n. 1, p. 237-254, 2002.

TAYLOR, M.; SARNO, L. Capital Flows to Developing Countries: Long and Short-Term Determinants. The World Bank Economic Review, v. 11, n. 3, 1997.

WINDMEIJER, F. A finite sample correction for the variance of linear efficient two-step GMM estimators. Journal of Econometrics, n. 126, p.25-51, 2005.

WOOLDRIDGE, J. M. Econometric analysis of Cross Section and Panel Data. Massachusetts: The MIT Press, 2007.

WORLD DEVELOPMENT. v.39, n.5, May 2011, p. 712-724.

YING, Y-H.; KIM, Y. An Empirical Analysis on Capital Flows: The Case of Korea and Mexico. Southern Economic Journal, v.67, n.4, 2001.

\section{Fontes de dados}

Chicago Board Options Exchange. Disponível em: cboe.com.

Federal Reserve Bank of Sant Louis. Disponível em: www.stlouisfed.org.

International Monetary Fund, International Financial Statistic. Disponível em:www.imf.org/ en/Data.

International Monetary Fund, World Economic Outlook Databases.Disponível em: www. imf.org.

World Bank, World Development Indicators. Disponível em:data.worldbank.org/.

\section{Sobre os autores}

Mauricio AndradeWeiss - mauricio.weiss@ufrgs.br

Professor Adjunto da Faculdade de Ciências Econômicas da Universidade Federal do Rio Grande do Sul, Porto Alegre, Rio Grande do Sul.

Daniela Magalhães Prates - prates@unicamp.br

Professora Associada do Instituto de Economia da Universidade Estadual de Campinas, Campinas, São Paulo;

Pesquisadora do CNPq.

\section{Sobre o artigo}

Recebido em 30 de dezembro de 2014. Aprovado em 28 de abril de 2016. 


\section{Apêndice 1}

Tabela A1 Resultados dos testes de exogeneidade estrita

\begin{tabular}{|c|c|c|c|c|c|c|c|c|}
\hline \multirow[b]{2}{*}{ Variável } & \multicolumn{2}{|r|}{ FEGLS } & \multicolumn{2}{|r|}{$\mathbf{F E}$} & \multicolumn{2}{|r|}{$\mathbf{R E}$} & \multicolumn{2}{|r|}{ FD } \\
\hline & Qui2 & $\begin{array}{r}\text { Prob }> \\
\text { chi2 }\end{array}$ & Qui2 & $\begin{array}{r}\text { Prob > } \\
\text { chi2 }\end{array}$ & Qui2 & $\begin{array}{r}\text { Prob }> \\
\text { chi2 }\end{array}$ & Qui2 & $\begin{array}{r}\text { Prob > } \\
\text { chi2 }\end{array}$ \\
\hline câmbio & 0,00 & 0,9536 & 1,60 & 0,2167 & 0,22 & 0,6427 & 0,00 & 0,9847 \\
\hline reservas_next & 0,35 & 0,5549 & 1,05 & 0,3133 & 0,10 & 0,7531 & 0,75 & 0,3852 \\
\hline detpe_next & 0,12 & 0,7282 & 0,04 & 0,8426 & 0,31 & 0,5770 & 0,05 & 0,8238 \\
\hline dividai_next & 0,20 & 0,6557 & 0,52 & 0,4752 & 2,07 & 0,1503 & 0,07 & 0,7931 \\
\hline jurosd_next & 0,08 & 0,7732 & 0,07 & 0,7938 & 0,00 & 0,9623 & 0,50 & 0,4780 \\
\hline tc_next & 0,27 & 0,6025 & 0,27 & 0,6089 & 1,00 & 0,3181 & 0,38 & 0,5363 \\
\hline inflacão_next & 0,85 & 0,3576 & 0,17 & 0,6853 & 0,15 & 0,6949 & 0,51 & 0,4746 \\
\hline pib2005_next & 0,06 & 0,8021 & 0,01 & 0,9118 & 1,40 & 0,2360 & 0,67 & 0,4134 \\
\hline
\end{tabular}

Fonte: elaboração própria a partir de resultados obtidos no Stata 12. 